\title{
Cationic water dispersion of bio-sourced crosslinked polyurethane
}

\author{
Laurence Pessoni, ${ }^{\mathrm{a}, \mathrm{b}}$ Prakash Sane, ${ }^{\mathrm{a}, \mathrm{b}}$ Etienne Grau, ${ }^{* a, b}$ Henri Cramail ${ }^{* a, b}$ \\ aUniversity of Bordeaux, Laboratoire de Chimie des Polymères Organiques, UMR 5629, Bordeaux INP/ \\ ENSCBP, 16 avenue Pey Berland, Pessac Cedex, France \\ ${ }^{b}$ Centre National de la Recherche Scientifique, Laboratoire de Chimie des Polymères Organiques, UMR \\ 5629, Pessac Cedex, France \\ Corresponding author : egrau@enscbp.fr
}

\section{ABSTRACT}

A series of crosslinkable waterborne polyurethanes (WPU) from bio-sourced diol were synthesized by the acetone process. WPU raise much interest in coating and adhesives application due to its low volatile organic compounds emission. Crosslinking of the obtained PU film should improve mechanical properties and water and solvent resistance. In this study, $\mathrm{N}$-methyldiethanolamine (MDEA), the emulsifier, was used as short hydrophilic diol to obtain a cationic dispersion after quaternization with acetic acid. The crosslinker, $\mathrm{N}$-4-vinylbenzyl-diethanolamine (VBDEA) synthesized in this study, also contains a tertiary amine which can improve dispersion in addition to the mechanical properties. Finally, a telechelic diol (Priplast 1900) obtained by polyesterification of dimer fatty acid was used as long hydrophobic diol. Stable PU water dispersions ( $40 \mathrm{wt} \%$ ) were obtained by acetone process with various diisocyanates 'HMDI, HDI and IPDI) and characterized by DLS. After complete evaporation of water, films were obtained from these dispersions. Then, the films were crosslinked by solar irradiation. The network formation was confirmed 
using swelling test in acetone and THF. Films were compared after and before irradiation demonstrated that irradiation improves solvent and water resistance but also mechanical properties of each film.

\section{INTRODUCTION}

Polyurethanes (PU) are employed for many applications such as coating, ink, adhesives, rubbers plastic or textiles. ${ }^{1-6}$ Due to the environmental requirements in these days, waterborne polyurethanes (WPU) are more and more developed due to its low volatile organic compounds emission and have much interest in coating and adhesives application. ${ }^{4}$ In industry, different synthetic routes were developed to obtain PU dispersions such as the melt, the cetimine-cetazine, the acetone, and the prepolymer emulsification processes. ${ }^{4-10}$ The most commonly used are the prepolymer emulsification ${ }^{11-15}$ and acetone processes. ${ }^{16-}$

${ }^{20}$ Most of these processes require the incorporation of internal emulsifiers within the PU backbone to disperse it in water..$^{4,5,7,21,22}$ These species are usually a diol with an ionic group such as a carboxylate, ${ }^{8,11-}$ 14,16,23-25 a sulfonate ${ }^{17}$, a quaternary ammonium, ${ }^{26-29}$ phosphonium ${ }^{30,31}$ or non-ionic groups as poly(ethylene oxide). ${ }^{7}$ The most used emulsifier is the 2,2-Bis(hydroxymethyl)propionic acid (DMPA). After incorporation of DMPA along the chain of PU, a base group as trimethylamine (TEA) is used to neutralize the carboxylate acid and allow the anionic dispersion. The cationic dispersion is also mainly used. In this case, the most common emulsifier used is $\mathrm{N}$-methyldiethanolamine (MDEA). It has a quaternary ammonium which is principally quaternized by acetic acid.

Crosslinking of the PU film obtained after synthesis is mainly used to improve mechanical properties and chemical and water resistance. ${ }^{18,22,32-41}$ Usually, UV-cured waterborne technology is used by industrial due to the less environmental impact. ${ }^{4}$ In order to obtain a crosslinked film, three components are usually used an oligomer (e.g., acrylated polyurethane), a photoinitiator and a reactive diluent. ${ }^{4,34,36,42}$ The reactive diluent is used principally to control the viscosity of the system and to control the UV-curable 
speed. Usually, reactive diluents are acrylate or methacrylate. ${ }^{42}$ The photoinitiator absorbed UV light to produce free radicals to crosslink the film by the reaction between the prepolymer and reactive diluent.

This study aims to crosslink waterborne polyurethane with only one component to reduce chemical product as the team of Duncan J. Maitland ${ }^{43}$ who synthetized a DEA-diol monomer from diethanolamine and allyl chlroformate to crosslink by electron-bean polyurethanes prepared in bulk. This custom DEA-diol was also compared with a commercially available trimethylolpropane allyl ether and the 2-butene-1,4diol. The custom DEA-diol allows improving thermomechanical properties of shape memory polymer systems. Herein, a styrenic crosslinker, with two hydroxyl function was synthesized and copolymerized with a diol and an emulsifier. The polyurethane synthesized was obtained by the acetone process in one step. The diol used was an amorphous bio-sourced polyester diol. The crosslinker used was the $\mathrm{N}$-4vinylbenzyl-diethanolamine (VBDEA) synthetized according to previous studies. ${ }^{44,45}$ MDEA was chosen as emulsifier. MDEA is quaternized with acetic acid in order to obtain a cationic dispersion. The advantage of this kind of dispersion is that the crosslinker can also be quaternized ( $p K a(M D E A)=8.7$ and $\mathrm{pKa}(\mathrm{VBDEA})=8.4)$. Then, different isocyanates and different compositions were tested and compared in order to study the crosslinker effect and to find the better condition to obtain good dispersions and good film mechanical properties. Finally, PU dispersions and films were fully characterized.

\section{EXPERIMENTAL}

\section{Materials}

Diethanolamine ( $\geq 98.0 \%$ ) and 4-vinyl benzyl chloride (90\%), anhydrous magnesium sulfate ( $\geq 99.5 \%$, $\left.\mathrm{MgSO}_{4}\right), \mathrm{N}$-methyldiethanolamine ( $\geq 99 \%, \mathrm{MDEA}$ ) and acid acetic ( $\geq 99.7 \%$ ) were purchased from Sigma Aldrich. Triethanolamine ( $\geq 99 \%$, TEA) was obtained from Fisher Scientific. Dibutyltin dilaurate (>95\%, DBTDL) and Dicyclohexylmethane 4,4'-Diisocyanate (>90\%, mixture of isomers, HMDI) were supplied from TCl. The diol is an amorphous polyester diol $\left(\mathrm{Mn}=2000 \mathrm{~g} \mathrm{~mol}^{-1}\right.$, Priplast 1900$)$ kindly provided by 
CRODA. Acetone (CHROMASOLV ${ }^{\circledR}$, for HPLC, $\geq 99.8 \%$ ), Tetrahydrofuran (anhydrous, $\geq 99.9 \%$, contains 250 ppm BHT as inhibitor, THF), N,N-Dimethylformamide (CHROMASOLV ${ }^{\circledR}$ Plus, for HPLC, $\geq 99.9 \%$, DMF) and Dichloromethane (CHROMASOLV ${ }^{\circledR}$ Plus, for HPLC, $\geq 99.9 \%$, DCM) were purchased from SigmaAldrich. All products were used as received.

\section{Synthesis of $\mathbf{N}$-4-vinylbenzyl-diethanloamine (VBDEA)}

The experimental procedure described in Figure 1 was adapted from the work of Jin et al. ${ }^{45} \mathrm{In}$ a $250 \mathrm{~mL}$ round-bottom flask, diethanolamine $(10.0 \mathrm{~g}, 95.2 \mathrm{mmol})$ was added in DMF $(50 \mathrm{~mL})$. To this solution, TEA $(9.62 \mathrm{~g}, 95.2 \mathrm{mmol})$ and a stirring bar were added. The resulting solution was stirred at $60^{\circ} \mathrm{C}$ for $20 \mathrm{~min}$ to get a homogeneous mixture. At the end of this period, 4-vinyl benzyl chloride (14.48 g, $95.2 \mathrm{mmol})$ was added to the mixture. After $10 \mathrm{~h}$ at $60^{\circ} \mathrm{C}$, the reaction mixture was cooled to room temperature, filtered, and most of the DMF was removed under reduced pressure. Then, the filter liquor was washed with water and extracted with DCM. The organic layer was dried with anhydrous $\mathrm{MgSO}_{4}$ and concentrated under vacuum to give a yellow liquid. ${ }^{1} \mathrm{H}$ NMR $\left(400 \mathrm{MHz}, \mathrm{CDCl}_{3}, \delta \mathrm{ppm}\right): 2.30(\mathrm{~s}, 2 \mathrm{H},-\mathrm{O} \underline{\mathrm{H}}), 2.63-2.66(\mathrm{t}, 4 \mathrm{H}$, $\left.-\mathrm{N}-\underline{\mathrm{C}}_{2}-\mathrm{CH}_{2}-\mathrm{OH}\right), 3.54-3.56\left(\mathrm{t}, 4 \mathrm{H},-\mathrm{N}-\mathrm{CH}_{2}-\underline{\mathrm{H}}_{2}-\mathrm{OH}\right), 3.62\left(\mathrm{~s}, 2 \mathrm{H},-\Phi-\mathrm{C} \underline{H}_{2}-\mathrm{N}-\right), 5.14-5.17$ (d, $1 \mathrm{H}$,

$\left.-\mathrm{CH}=\underline{\mathrm{C}}_{2}\right), 5.64-5.68\left(\mathrm{~d}, 1 \mathrm{H},-\mathrm{CH}=\underline{\mathrm{C}}_{2}\right),\left(\mathrm{dd}, 1 \mathrm{H},-\Phi-\mathrm{C} \underline{\mathrm{H}}=\mathrm{CH}_{2}\right), 7.19-7.21$ (d, $\left.-\mathrm{CH}_{2}-\mathrm{C}-\mathrm{C} \underline{H}(\underline{\mathrm{CH}})-\right)$, 7.29-7.30 (d, $-\underline{\mathrm{C}}(\underline{\mathrm{C}} \underline{\mathrm{H}})-\mathrm{C}-\mathrm{CH}-)$ (Figure $\mathrm{S} 1$ in supplementary data). 


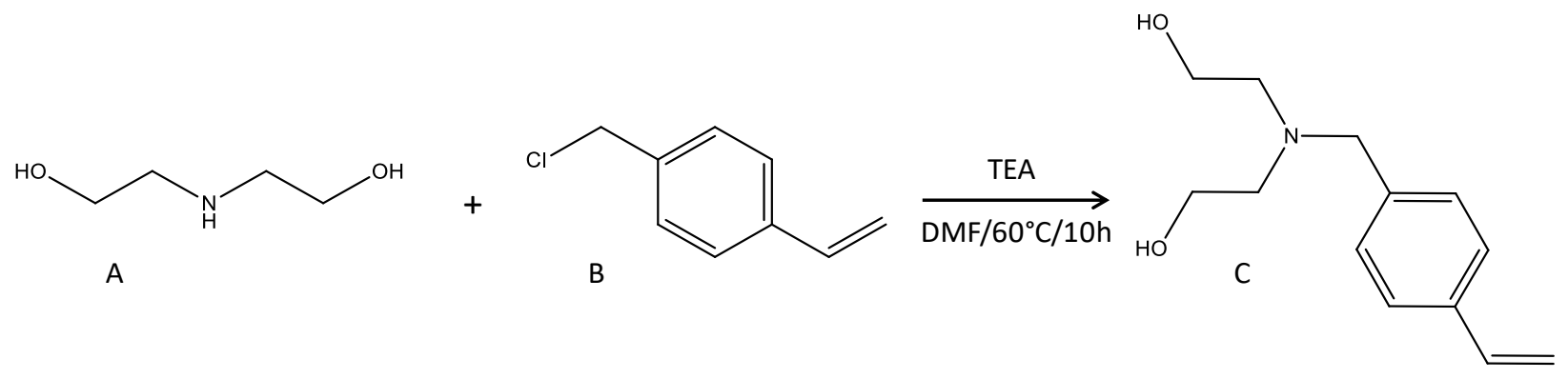

Figure 1. Formation of $\mathrm{N}$-4-vinylbenzyl-diethanolamine (C) from the diethanolamine (A) and the 4-vinyl benzyl chloride (B).

\section{Preparation of WPU dispersions}

Diols, Priplast 1900, $\mathrm{N}$-methyldiethanolamine and VBDEA were first inserted in $40 \mathrm{~mL}$ of acetone into a $250 \mathrm{~mL}$ double-neck round bottom flask with a reflux condenser and a mechanical stirrer (150 tr. $\left.\mathrm{min}^{-1}\right)$. The mixture is stirred for $10 \mathrm{~min}$ at $80^{\circ} \mathrm{C}$. Then, the DBTDL ( $1 \%$ weight of solid content) in $10 \mathrm{~mL}$ of acetone was added to the mixture. After $10 \mathrm{~min}$, the polyaddition starts with the introduction of the isocyanate (1.1 eq of $\mathrm{OH}$ ) mixed with $30 \mathrm{~mL}$ of acetone. After $5 \mathrm{~h}$ at $80^{\circ} \mathrm{C}$, the reaction mixture was cooled to room temperature. Then, the prepolymer was neutralized by addition of acetic acid (1.1 eq of MDEA). After 30 min at ambient temperature, water was added droplet by droplet under a strong stirring (500 tr.min $\left.{ }^{-1}\right)$. After $30 \mathrm{~min}$, acetone was evaporated by rotary vacuum evaporation to obtain an aqueous dispersion of PU (WPU) with a solid content of $40 \%$. All experiments were prepared using the same procedure and based on the mixing plot represented in Figure 2. The compositions of WPU are summarized in Table 1. 




Figure 2. Schematic representation of the proportion of diol (a), crosslinker (b) and emulsifier (c) in the different dispersion; numbers represent the name of each sample described in Table 1.

Table 1. Diol composition of WPU. Hard segment correspond to the proportion of VBDEA and MDEA

\begin{tabular}{cccccc}
\hline Sample & $\begin{array}{c}\text { Priplast } \\
(\mathrm{mmol})\end{array}$ & $\begin{array}{c}\text { VBDEA } \\
(\mathrm{mmol})\end{array}$ & $\begin{array}{c}\text { MDEA } \\
(\mathrm{mmol})\end{array}$ & $\begin{array}{c}\text { MDEA segment } \\
(\% \mathrm{~mol})\end{array}$ & $\begin{array}{c}\text { Hard segment } \\
(\% \mathrm{~mol})\end{array}$ \\
\hline 1 & 3.0 & - & 1.5 & 33 & 33 \\
2 & 3.0 & - & 3.0 & 50 & 50 \\
3 & 3.0 & - & 6.0 & 66 & 66 \\
4 & 3.0 & 1.5 & 2.25 & 33 & 55 \\
5 & 3.0 & 3.0 & 3.0 & 33 & 66 \\
6 & 3.0 & 6.0 & 4.5 & 33 & 78 \\
7 & 3.0 & 1.5 & 4.5 & 50 & 66 \\
8 & 3.0 & 3.0 & 6.0 & 50 & 75 \\
9 & 3.0 & 6.0 & 9.0 & 50 & 83 \\
10 & 3.0 & 1.5 & 9.0 & 66 & 78 \\
11 & 3.0 & 3.0 & 12.0 & 66 & 83 \\
12 & 3.0 & 6.0 & 18.0 & 66 & 89 \\
\hline
\end{tabular}

\section{Preparation of WPU films}

The PU films were prepared by filling a Teflon mold ( $50 \mathrm{~mm} \times 70 \mathrm{~mm} \times 4 \mathrm{~mm}$ ) with the WPU aqueous dispersion. After $48 \mathrm{~h}$ under ambient condition, PU films were obtained with thickness around $0.5 \mathrm{~mm}$. 
Crosslinked films were obtained by an exposure under a solar simulator (Newport, $146 \mathrm{~W}$ ) during $5 \mathrm{~h}$. Samples were placed to receive one-sun intensity.

\section{Characterization}

NMR experiments were performed at $298 \mathrm{~K}$ on a Bruker Avance 400 spectrometer operating at $400 \mathrm{MHz}$, in $\mathrm{CDCl}_{3}$.

Size exclusion chromatography (SEC) was performed in DMF on a GPC 50 from Agilent equipped with a series of three columns from Shodex (KD-G: guard column, 4.6 × $10 \mathrm{~mm}$; two KD-804: 8 × $300 \mathrm{~mm}$ ). The DMF HPLC grade solvent with $1 \mathrm{~g} \cdot \mathrm{L}^{-1}$ of $\mathrm{LiBr}$ was used as eluent at $50^{\circ} \mathrm{C}$ and a flow rate of $0.8 \mathrm{~mL} \cdot \mathrm{min}^{-1}$. The elution of the filtered samples was monitored using simultaneous refractive index and UV detection. Number-average molar mass $(\mathrm{Mn})$ and dispersity ( $=\mathrm{Mw} / \mathrm{Mn}$, where $\mathrm{Mw}$ is the mass-average molar mass) of the polymers were calculated from a calibration derived from polystyrene standards. The polymer samples were prepared at $5 \mathrm{~g} . \mathrm{L}^{-1}$ and filtered through $0.45 \mu \mathrm{m}$ PTFE filters.

Infrared spectra (FTIR-ATR) were obtained on a Bruker-Tensor 27 spectrometer, equipped with a diamond crystal, using the attenuated total reflection mode. The spectra were acquired using 16 scans at a resolution of 4 wavenumbers.

Differential Scanning Calorimetry (DSC) measurements were performed on DSC Q100 (TA Instruments). The sample was heated from $-80^{\circ} \mathrm{C}$ to $120^{\circ} \mathrm{C}$ at a rate of $10{ }^{\circ} \mathrm{C} \cdot \mathrm{min}^{-1}$. Consecutive cooling and second heating run were also performed at $10^{\circ} \mathrm{C} \cdot \mathrm{min}^{-1}$. The glass transition temperatures were calculated from the second heating run.

Thermogravimetric analyses (TGA) were performed on TGA-Q500 system from TA instruments at a heating rate of $10^{\circ} \mathrm{C} \cdot \mathrm{min}^{-1}$ under nitrogen atmosphere from room temperature to $600^{\circ} \mathrm{C}$. 
The tensile strength, Young's modulus, and elongation at the break were measured by using the Traction MTS QTest $25(0.75 \pm 0.25)$ machine at a crosshead speed of $100 \mathrm{~mm} \cdot \mathrm{min}^{-1}$ with $4 \mathrm{~mm}$ width for all samples.

The water and solvent resistance were characterized by the solvent swelling. Films were dipped in deionized water, acetone, and THF at room temperature during one week. Percentage of the soluble part and solvent absorption were calculated by using equation 1 and 2 respectively.

$$
\begin{gathered}
S=\frac{w_{s}}{w_{i}} \times 100 \\
Q=\frac{w_{f}-w_{d}}{w_{d}} \times 100
\end{gathered}
$$

where $\mathrm{S}$ is the soluble part of the sample in acetone or THF, $\mathrm{w}_{\mathrm{s}}$ is the weight of the soluble part after drying, $w_{i}$ is the weight of the film before dipped; $Q$ is solvent absorption in $\%$ and $w_{f}$ is the weight of the film after swelling and $w_{d}$ is the weight of the dry film after swelling.

The surface energy and the contact angles of water, diiodomethane and ethylene glycol were measured with a contact angle goniometer with a J1H high speed camera (CCD camera type 8420 assembled) using the sessile-drop method at $25^{\circ} \mathrm{C}$. The software used was Drope Shape Analysis DSA for Windows (TM), DSA version 1.90.1.14 (HS).

TEM were carried on a Hitachi $\mathrm{H} 7650$ microscope with an acceleration voltage of $80 \mathrm{kV}$ and images were acquired with an ORIUS SC1000 11 MPx Camera. Samples were prepared by nebulizing dispersions of NPs at concentrations of $1 \mathrm{~g} \mathrm{~L}^{-1}$ on Formvar/Carbon 200 mesh copper grids from Agar Scientific and leaving them to dry at room temperature.

\section{RESULTS AND DISCUSSION}

\section{Elaboration and characterization of PU dispersions}


PU emulsions were prepared according to the procedure shown in Figure 3. WPUs were obtained from an isocyanate (A: HDI, B: IPDI, C: HMDI or D: MDI), a diol (E: Priplast 1900 an amorphous bio-based polyester diol), an emulsifier (F: MDEA) and a crosslinker (G: VBDEA) following the acetone process. The first step consists of a polymerization in acetone. Then, a step of neutralization with acetic acid is realized. Water is then slowly added on the mixture to obtain a dispersion in water and acetone. Finally, acetone is removed by evaporation under vacuum leading to a PU water dispersion with $40 \%$ of solid content. The absence of isocyanate is controlled by FTIR-ATR. Indeed, after $5 \mathrm{~h}$ of polymerization, residual isocyanate (peak at $2275 \mathrm{~cm}^{-1}$ ) are still present as expected since an excess of 1.1 eq. of NCO per OH was used but after addition of water, isocyanate was completely hydrolyzed and undetectable by FTIR analysis (see Figure S2 in supplementary data). Molecular masses were controlled in GPC with DMF as solvent, Mn obtained after hydrolysis are around $16000 \mathrm{~g} \mathrm{~mol}^{-1}$ for PU obtained with IPDI, $18000 \mathrm{~g} \mathrm{~mol}^{-1}$ for PU obtained with MDI and $27000 \mathrm{~g} \mathrm{~mol}^{-1}$ for PU obtained with HDI and HMDI (see Table S1 in supplementary data). 


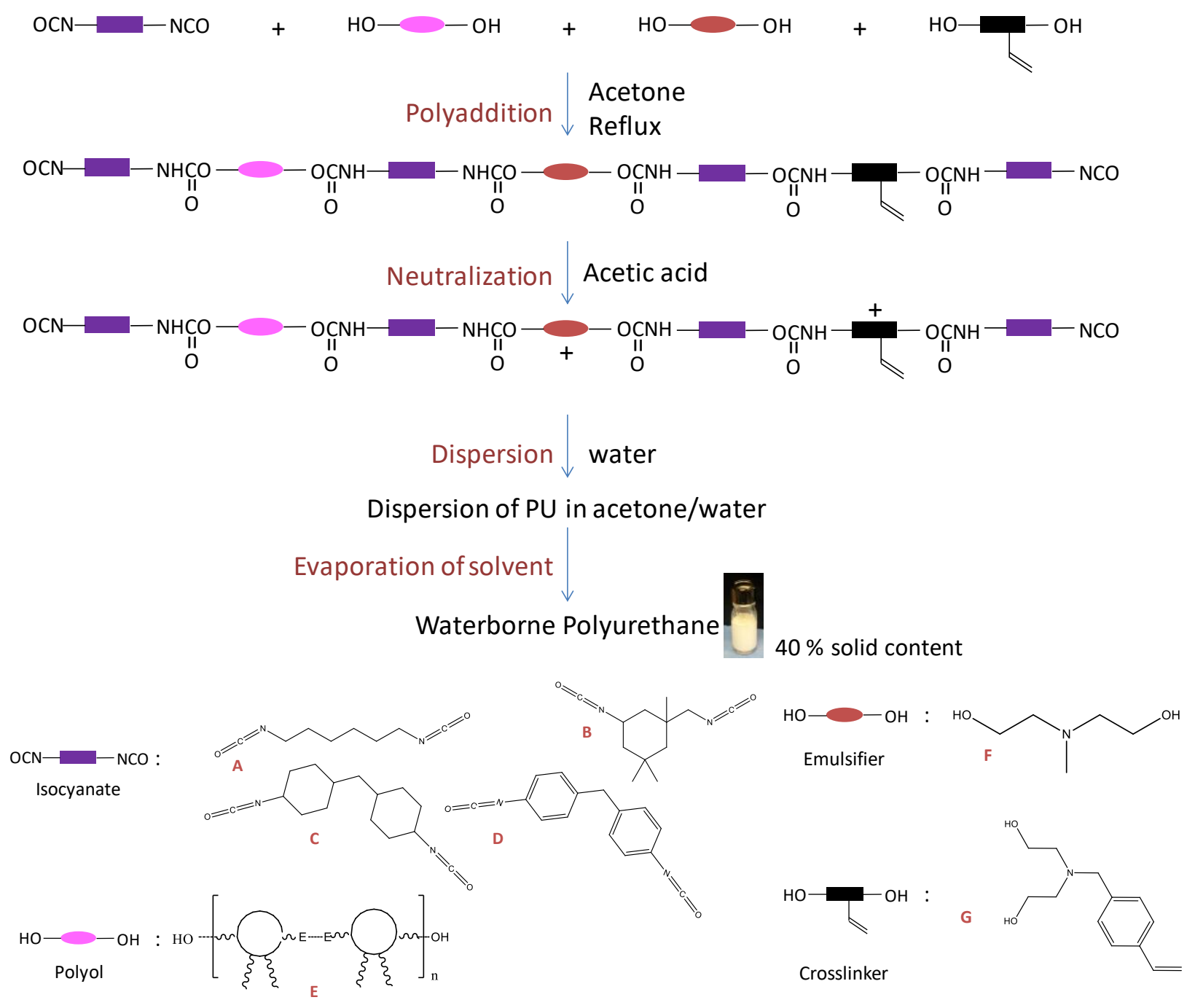

Figure 3. Scheme illustration on the different steps of the preparation of the aqueous dispersion of PU;

(A) HDI, (B) IPDI, (C) HMDI, (D) MDI, (E) Priplast 1900: amorphous polyester diol, (F) MDEA and (G)

VBDEA.

Dispersions have been obtaining in all cases, but they are more or less stable over time. In Table 1 are shown the appearance and the particles size of the PU dispersion after six months at room temperature. All isocyanates, except MDI, lead to stable dispersion. For MDI, a formation of cream is observed within few months. In each case, dispersions were obtained with sample 7 to 12 which contained the highest fraction of emulsifier with particle size in the range of $20-200 \mathrm{~nm}$. 
TEM images in Figure 4 and S3 confirm the presence of PU particles. However, the particle sizes are overestimated compared to the DLS analysis, $80 \mathrm{~nm}$ vs $120 \mathrm{~nm}$. This may be due to the low $\mathrm{Tg}$ of the PU obtained (around $-40^{\circ} \mathrm{C}$ ) leading to a flattening of the spherical particles on the TEM grid.

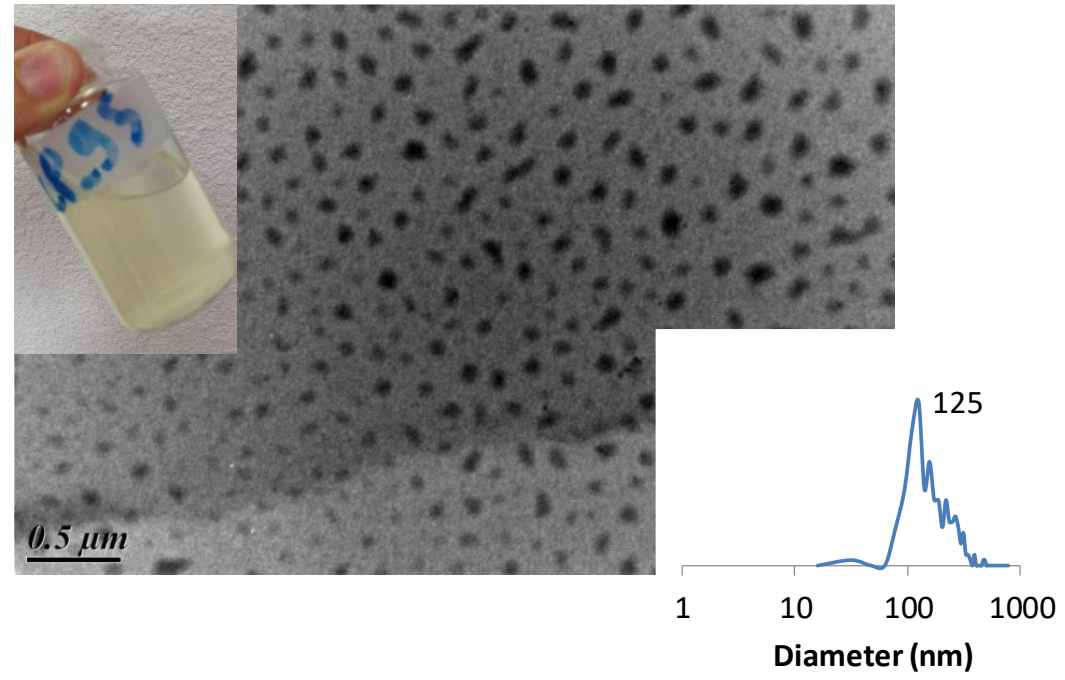

Firgure 4. TEM image and TEM particles size distribution of WPU dispersion realized with HDI (sample 10). 
Table 2. Average particle sizes and appearance after six months of WPU obtained with HDI and MDI as isocyanate.

\begin{tabular}{|c|c|c|c|c|c|c|c|c|c|c|c|c|}
\hline & \multicolumn{3}{|c|}{ HMDI } & \multicolumn{3}{|c|}{ HDI } & \multicolumn{3}{|c|}{ IPDI } & \multicolumn{3}{|c|}{$\mathrm{MDI}$} \\
\hline Sample & $\begin{array}{c}\text { Appearance } \\
>5 \text { month }\end{array}$ & $\begin{array}{c}\text { Particle } \\
\text { size }(n m)^{1}\end{array}$ & PDI & $\begin{array}{c}\text { Appearance } \\
>5 \text { month }\end{array}$ & $\begin{array}{c}\text { Particle } \\
\text { size }(n m)^{1}\end{array}$ & PDI & $\begin{array}{c}\text { Appearance } \\
>5 \text { month }\end{array}$ & $\begin{array}{c}\text { Particle } \\
\text { size }(n m)^{1}\end{array}$ & PDI & $\begin{array}{c}\text { Appearance } \\
>5 \text { month }\end{array}$ & $\begin{array}{c}\text { Particle } \\
\text { size }(n m)^{1}\end{array}$ & PDI \\
\hline 1 & Precipitate & - & - & Aggregate & - & - & Precipitate & - & - & Precipitate & - & - \\
\hline 2 & Precipitate & - & - & $\begin{array}{c}\text { Semi- } \\
\text { transparent }\end{array}$ & 39 & 0.581 & White & 42 & 0.139 & Precipitate & - & - \\
\hline 3 & $\begin{array}{c}\text { Semi- } \\
\text { transparent }\end{array}$ & 28 & 0.105 & $\begin{array}{c}\text { Semi- } \\
\text { transparent }\end{array}$ & 68 & 0.401 & Transparent & 26 & 0.142 & Cream & - & - \\
\hline 4 & precipitate & - & - & Aggregate & - & - & Precipitate & - & - & precipitate & - & - \\
\hline 5 & precipitate & - & - & Aggregate & - & - & Precipitate & - & - & precipitate & - & - \\
\hline 6 & White & 179 & 0.682 & White & 140 & 0.325 & Precipitate & - & - & Cream & - & - \\
\hline 7 & White & 60 & 0.149 & $\begin{array}{c}\text { Semi- } \\
\text { transparent }\end{array}$ & 33 & 0.536 & White & 107 & 0.154 & Cream & - & - \\
\hline 8 & White & 38 & 0.253 & $\begin{array}{c}\text { Semi- } \\
\text { transparent }\end{array}$ & 30 & 0.741 & White & 37 & 0.198 & Cream & - & - \\
\hline 9 & $\begin{array}{c}\text { Semi- } \\
\text { transparent }\end{array}$ & 117 & 0.895 & $\begin{array}{c}\text { Semi- } \\
\text { transparent }\end{array}$ & 25 & 0.839 & White & 96 & 0.202 & Cream & - & - \\
\hline 10 & $\begin{array}{c}\text { Semi- } \\
\text { transparent }\end{array}$ & 40 & 0.124 & $\begin{array}{c}\text { Semi- } \\
\text { transparent }\end{array}$ & 65 & 0.283 & $\begin{array}{c}\text { Semi- } \\
\text { transparent }\end{array}$ & 21 & 0.292 & Cream & - & - \\
\hline 11 & $\begin{array}{c}\text { Semi- } \\
\text { transparent }\end{array}$ & 43 & 0.299 & $\begin{array}{c}\text { Semi- } \\
\text { transparent }\end{array}$ & 22 & 0.390 & $\begin{array}{c}\text { Semi- } \\
\text { transparent }\end{array}$ & 39 & 0.332 & Cream & - & - \\
\hline 12 & White & 83 & 0.301 & $\begin{array}{c}\text { Semi- } \\
\text { transparent }\end{array}$ & 260 & 0.435 & $\begin{array}{c}\text { Semi- } \\
\text { transparent }\end{array}$ & 44 & 0.415 & Cream & - & - \\
\hline
\end{tabular}

${ }^{1}$ Diameter of particle size in volume determined by DLS 


\section{Elaboration and study of films properties}

Films were realized directly after synthesis, even for unstable dispersion. Therefore, WPU film can be obtained whatever the stability of the dispersion. In this section, thermal and mechanical properties of the films were compared before and after irradiation under a solar simulator.

\section{Thermal analysis of WPU films}

An example of a thermogravimetric (TGA) curve is shown in Figure 5 and all compositions are described in supplementary data (Table S2). The decomposition temperature (Td) is taken when the weight loss is $5 \%$. For each sample, the degradation is slow, between $\sim 200^{\circ} \mathrm{C}$ and $\sim 500{ }^{\circ} \mathrm{C}$. Composition in diols and isocyanate nature have no significant influence on the $\mathrm{Td}\left(210-270^{\circ} \mathrm{C}\right)$ and no differences were observed before and after crosslinking.



Figure 5. Example of thermograph of WPU before (green) and after (red) UV (sample 11 with HMDI as diisocyanate); solid line corresponds to the loss of weight and dashed line corresponds to the derivative weight. 
In DSC analysis (Table 3 and S3) shows that Tg is mainly impacted by the structure of the isocyanate used: $\operatorname{Tg}(I P D I) \approx \operatorname{Tg}(H D I)<\operatorname{Tg}(H M D I)<\operatorname{Tg}(\mathrm{MDI})$. In all cases, $\operatorname{Tg}$ of the $\mathrm{PU}$ remains low (from $-38^{\circ} \mathrm{C}$ to $\left.-50^{\circ} \mathrm{C}\right)$. Again irradiation has no significant effect on the Tg.

Table 3 Tg of WPU films before and after irradiation determined by DSC.

\begin{tabular}{lcccc}
\hline & $\mathrm{HDI}$ & $\mathrm{MDI}$ & $\mathrm{HMDI}$ & IPDI \\
\hline Before & $-49.9 \pm 1.0^{\circ} \mathrm{C}$ & $-38.4 \pm 2.3^{\circ} \mathrm{C}$ & $-46.9 \pm 1.7^{\circ} \mathrm{C}$ & $-46.4 \pm 2.9^{\circ} \mathrm{C}$ \\
crosslinking & $-50.2 \pm 1.8^{\circ} \mathrm{C}$ & $-37.7 \pm 4.0^{\circ} \mathrm{C}$ & $-45.9 \pm 1.8^{\circ} \mathrm{C}$ & $-46.3 \pm 1.4^{\circ} \mathrm{C}$ \\
\hline After crosslinking & & &
\end{tabular}

\section{Solvent resistance of WPU films}

Swelling tests were realized in THF and acetone to confirm the formation of a network after irradiation. The results shown in Figure 6Erreur ! Source du renvoi introuvable. and S5 demonstrated that the films obtained are partially crosslinked. As expected the gel fraction is directly proportional to the amount of crosslinker used. In the best case (sample 6) there is only $6 \%$ of the soluble part of the sample in acetone and $11 \%$ in THF. WPU films obtained with IPDI and HDI exhibit similar behavior than film obtained with HMDI. Even though films are not entirely crosslinked, films obtained with HDI, HMDI, and IPDI conserved its shape upon swelling (see Figure 7). It should be noted that in the case of PUs which do not contain any VBDEA as crosslinker (samples 1-3) or the PU films before crosslinking the total solubilization was observed within one day. 



Figure 6. Percentage of soluble part of films (S) obtained from HMDI acetone (left) and THF (right); a: diol, b: crosslinker and c: MDEA.
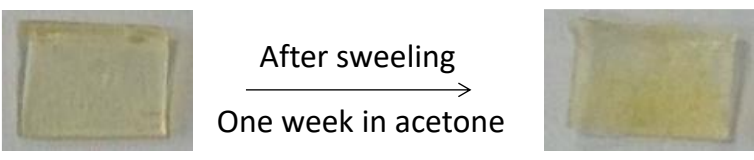

Figure 7. Photo of film obtained from sample 8 realized with HMDI before swelling (left) and after (right)

$$
\text { in acetone }
$$

\section{Water resistance of WPU films}

\section{Contact angle and surface energy}

In Table 4, the water contact angle and surface energy of each family of PU are represented before irradiation and after irradiation. Diols ratio and crosslinking of the film have no visible effect on these properties. Indeed, in each case, a hydrophilic surface with contact angle between $56.2 \pm 1.2^{\circ}$ and $84.8 \pm 1.1^{\circ}$, and surface energy between $30.9 \pm 0.3 \mathrm{mN} \cdot \mathrm{m}^{-1}$ and $49.8 \pm 0.7 \mathrm{mN} \cdot \mathrm{m}^{-1}$ is obtained. The film with the highest hydrophilicity and surface energy were obtained with IPDI; the lowest with HDI.

Table 4. Average water contact angle and surface energy of each family of PU before irradiation and after irradiation. 


\begin{tabular}{c|c|c|c|c|c|c|c|c}
\hline & \multicolumn{2}{|c|}{ HMDI } & \multicolumn{2}{c|}{ IPDI } & \multicolumn{2}{c|}{ MDI } & \multicolumn{2}{c}{ HDI } \\
\cline { 2 - 9 } & $\begin{array}{c}\text { Before } \\
\text { UV }\end{array}$ & After UV & $\begin{array}{c}\text { Before } \\
\text { UV }\end{array}$ & After UV & $\begin{array}{c}\text { Before } \\
\text { UV }\end{array}$ & After UV & $\begin{array}{c}\text { Before } \\
\text { UV }\end{array}$ & After UV \\
\hline $\begin{array}{c}\text { Water Contact } \\
\text { Angle }\end{array}$ & $71.4 \pm 1.6$ & $72.4 \pm 1.7$ & $60.5 \pm 1.1$ & $56.2 \pm 1.2$ & $82.4 \pm 0.8$ & $76.3 \pm 1.1$ & $84.8 \pm 1.1$ & $81.5 \pm 1.2$ \\
\hline $\begin{array}{c}\text { Surface Energy } \\
\left(\mathrm{mN} . \mathrm{m}^{-1}\right)\end{array}$ & $39.3 \pm 0.4$ & $38.5 \pm 0.2$ & $44.4 \pm 0.2$ & $49.8 \pm 0.7$ & $34.4 \pm 0.3$ & $33.8 \pm 0.5$ & $30.9 \pm 0.3$ & $32.7 \pm 0.4$ \\
\hline
\end{tabular}

Swelling test on water

In Erreur ! Source du renvoi introuvable. and S7 are represented water absorption (Q) of WPU. Irradiation of the film allows to dramatically decrease the water absorption except with MDI as diisocyanate where no change was observed. As expected the absorption is directly linked to the crosslinker ratio. As a result, crosslinked WPU films with water absorption below 5\% were obtained.
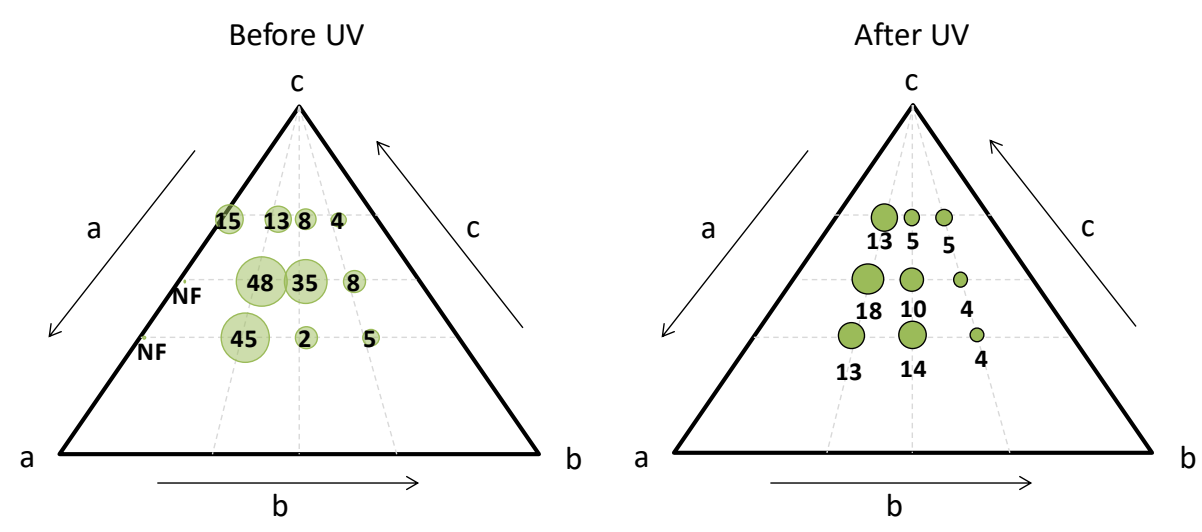

Figure 8. Water absorption of WPU film obtained with HMDI: $Q=\frac{w_{f}-w_{i}}{w_{i}} \times \mathbf{1 0 0}(\%) ; w_{f}=$ weight of the film after swelling; $w_{i}=$ initial weight of the film; a: polyol, b: crosslinker, c: MDEA and NF: No Film. 
Finally the mechanical properties of the PU films were determined. Whatever the isocyanate used, tensile strength and modulus are higher after irradiation (Erreur ! Source du renvoi introuvable. 5 and Figure 9, 10, and S6). For example, in the case of PU based on HMDI, the maximum of tensile strength and Young's modulus are respectively 7.7 and $125 \mathrm{MPa}$ while after irradiation its increase to 15 and $247 \mathrm{MPa}$.
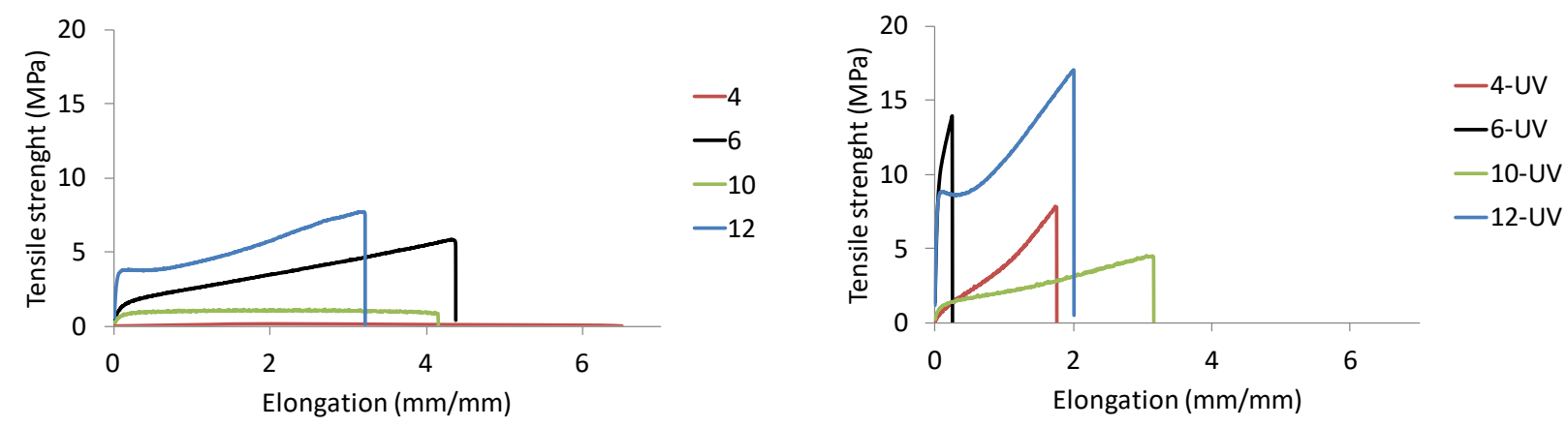

Figure 9. Tensile test of HMDI-based PU films before irradiation (left) and after irradiation (right); samples realized from HMDI as isocyanate (red: film 4, green: black: film 6, green: film 10 and blue:

film 12)

The deformation of each film tends to increase after irradiation if the deformation at break is inferior to approximatively $120-130 \%$ before irradiation. However, it will decrease if the initial deformation is over this value. For example, the deformation of the sample 6 obtained with HMDI has an elongation at the break at $23 \%$ before irradiation and $318 \%$ after irradiation. In contrary, the deformation of the sample 12 has an elongation at the break at $302 \%$ before irradiation and $147 \%$ after irradiation.

Table 5. Minimum and maximum value of tensile strength, elongation and modulus of each family of isocyanate with the crosslinker include on the composition; NF = No film

\begin{tabular}{c|c|c|c|c|c|c|c|c}
\hline & \multicolumn{2}{|c|}{ HMDI } & \multicolumn{2}{c|}{ IPDI } & \multicolumn{2}{c}{ MDI } & \multicolumn{2}{c}{ HDI } \\
\cline { 2 - 8 } & $\begin{array}{c}\text { Before } \\
\text { UV }\end{array}$ & After UV & $\begin{array}{c}\text { Before } \\
\text { UV }\end{array}$ & After UV & $\begin{array}{c}\text { Before } \\
\text { UV }\end{array}$ & After UV & $\begin{array}{c}\text { Before } \\
\text { UV }\end{array}$ & After UV \\
\hline $\begin{array}{c}\text { Tensile strength } \\
\text { (MPa) }\end{array}$ & $0.2-7.7$ & $3-15$ & NF-2.1 & $2-16$ & NF-2.4 & $0.3-4.6$ & $0.1-1$ & $0.9-5.4$ \\
Elongation (\%) & $120-784$ & $23-312$ & NF-322 & $12-344$ & NF-196 & $24-120$ & $16-1718$ & $31-197$
\end{tabular}


Tensile Strength (MPa)
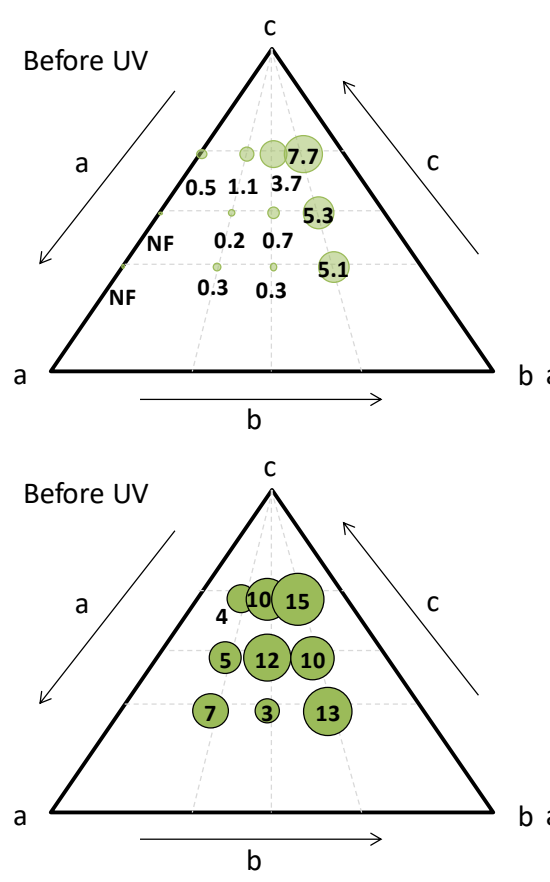

Elongation (\%)


Modulus (MPa)
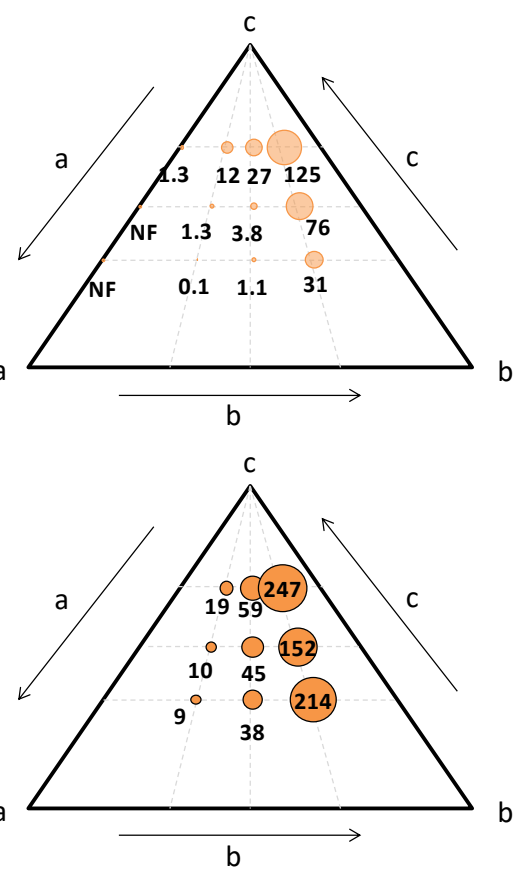

Figure 10. Mechanical properties of WPU films realized with HMDI before irradiation to the top and after irradiation to the bottom: in green is represented the tensile strength, in blue the elongation and in orange the modulus; a: diol, b: crosslinker and c: MDEA; NF = No film.

\section{CONCLUSIONS}

To conclude this study waterborne polyurethane (WPU) were synthesized from a bio-sourced diol by cationic dispersion using four isocyanates (HMDI, HDI, IPDI and MDI). These WPUs were obtained by the acetone process. N-4-vinylbenzyl-diethanolamine, was synthesized and incorporated in these WPU as internal UV crosslinker All isocyanate except MDI lead to a stable dispersion with solid content of $40 \mathrm{wt} . \%$. From these dispersions, homogeneous films were obtained by air-drying and their properties compared before and after irradiation under solar simulator. While thermal and surface properties remain 
unchanged by the crosslinking, the irradiation lead to an improvement of mechanical properties. Indeed, Tensile strength and Young's modulus increase after irradiation for all composition. To conclude, VBDEA appears to be a versatile crosslinker for WPU applications.

\section{ACKNOWLEDGEMENTS}

The authors thank University of Bordeaux, Bordeaux INP, CNRS, Aquitaine Regional Council and FUI for the financial support of this research. They also thank the Equipex Xyloforest ANR-10-EQPX-16 XYLOFOREST for flash chromatography.

\section{REFERENCES}

1. Engels, H. W.; Pirkl, H. G.; Albers, R.; Albach, R. W.; Krause, J.; Hoffmann, A.; Casselmann, H.; Dormish, J., Angewandte Chemie - International Edition 52, 94222013.

2. Avar, G.; Meier-Westhues, U.; Casselmann, H.; Achten, D. In Polymer Science: A Comprehensive Reference, 10 Volume Set, 2012.

3. Delebecq, E.; Pascault, J. P.; Boutevin, B.; Ganachaud, F., Chemical Reviews 113, 802013.

4. Noreen, A.; Zia, K. M.; Zuber, M.; Tabasum, S.; Saif, M. J., Korean Journal of Chemical Engineering 33, 3882016.

5. Zhou, X.; Li, Y.; Fang, C.; Li, S.; Cheng, Y.; Lei, W.; Meng, X., Journal of Materials Science and Technology 31, 7082015.

6. $\quad$ Noble, K. L., Progress in Organic Coatings 32, 1311997.

7. Dieterich, D., Progress in Organic Coatings 9, 2811981.

8. Kim, B. K., Colloid and Polymer Science 274, 5991996. 
9. Barni, A.; Levi, M., Journal of Applied Polymer Science 88, 7162003.

10. Madbouly, S. A.; Otaigbe, J. U., Progress in Polymer Science (Oxford) 34, 12832009.

11. Kim, B. K.; Lee, Y. M., Colloid \& Polymer Science 270, 9561992.

12. Visser, S. A.; Cooper, S. L., Polymer 33, 37901992.

13. Kwak, Y. S.; Kim, E. Y.; Yoo, B. H.; Kim, H. D., Journal of Applied Polymer Science 94, 17432004.

14. Nanda, A. K.; Wicks, D. A.; Madbouly, S. A.; Otaigbe, J. U., Journal of Applied Polymer Science 98, 25142005.

15. Athawale, V. D.; Kulkarni, M. A., Progress in Organic Coatings 67, 442010.

16. Li, Q. A.; Sun, D. C., Journal of Applied Polymer Science 105, 25162007.

17. Lewandowski, K.; Krepski, L. R.; Mickus, D. E.; Roberts, R. R.; Heilmann, S. M.; Larson, W. K.; Purgett, M. D.; Koecher, S. D.; Johnson, S. A.; McGurran, D. J.; Rueb, C. J.; Pathre, S. V.; Thakur, K. A. M., Journal of Polymer Science, Part A: Polymer Chemistry 40, 30372002.

18. Reischl, A.; Dieterich, D.; Witt, H.; Google Patents: 1973.

19. Cheng, K. L.; Chen, W. T.; Google Patents: 2001.

20. Chinwanitcharoen, C.; Kanoh, S.; Yamada, T.; Hayashi, S.; Sugano, S., Journal of Applied Polymer Science 91, 34552004.

21. Raut, K. G.; Bapat, S. P.; Tanavade, S. S., European Coatings Journal, 481999.

22. Mishra, V. K.; Patel, K. I., Journal of Dispersion Science and Technology 36, 3512015.

23. Chen, Y.; Chen, Y. L., Journal of Applied Polymer Science 46, 4351992.

24. Cakić, S. M.; Špírková, M.; Ristić, I. S.; B-Simendić, J. K.; M-Cincović, M.; Poręba, R., Materials Chemistry and Physics 138, 2772013.

25. Pérez-Limiñana, M. A.; Arán-Aís, F.; Torró-Palau, A. M.; Orgilés-Barceló, A. C.; Martín-Martínez, J. M., International Journal of Adhesion and Adhesives 25, 5072005.

26. Sukhawipat, N.; Saetung, N.; Saetung, A. in Key Engineering Materials: 2016, p 19. 
27. Daemi, H.; Rad, R. R.; Barikani, M.; Adib, M., Applied Catalysis A: General 468, 102013.

28. Gurunathan, T.; Rao, C. R. K.; Narayan, R.; Raju, K. V. S. N., Progress in Organic Coatings 76, 639 2013.

29. Chan, W. C.; Chen, S. A., Polymer 29, 19951988.

30. Zhang, M.; Hemp, S. T.; Allen, M. H.; Carmean, R. N.; Moore, R. B.; Long, T. E., Polymer Chemistry 5, 37952014 .

31. Williams, S. R.; Wang, W.; Winey, K. I.; Long, T. E., Macromolecules 41, 90722008.

32. Fang, Z. H.; Duan, H. Y.; Zhang, Z. H.; Wang, J.; Li, D. Q.; Huang, Y. X.; Shang, J. J.; Liu, Z. Y., Applied Surface Science 257, 47652011.

33. Wang, X.; Hu, Y.; Song, L.; Xing, W.; Lu, H.; Lv, P.; Jie, G., Journal of Polymer Research 18, 7212011.

34. Xu, J.; Rong, X.; Chi, T.; Wang, M.; Wang, Y.; Yang, D.; Qiu, F., Journal of Applied Polymer Science 130, 31422013.

35. Zhang, S.; Yu, A.; Song, X.; Liu, X., Progress in Organic Coatings 76, 10322013.

36. Yu, F.; Cao, L.; Meng, Z.; Lin, N.; Liu, X. Y., Polymer Chemistry 7, 39132016.

37. Zhang, Y.; Asif, A.; Shi, W., Progress in Organic Coatings 71, 2952011.

38. Bhusari, G. S.; Umare, S. S.; Chandure, A. S., Journal of Coatings Technology Research 12, 571 2015.

39. Zhang, S.; Chen, J.; Han, D.; Feng, Y.; Shen, C.; Chang, C.; Song, Z., Journal of Polymer Research 222015.

40. Yang, Z.; Wicks, D. A.; Hoyle, C. E.; Pu, H.; Yuan, J.; Wan, D.; Liu, Y., Polymer 50, 17172009.

41. Blank, W. J.; Tramontano, V. J., Progress in Organic Coatings 27, 11996.

42. Srivastava, A.; Agarwal, D.; Mistry, S.; Singh, J., Pigment and Resin Technology 37, 2172008.

43. Hearon, K.; Smith, S. E.; Maher, C. A.; Wilson, T. S.; Maitland, D. J., Radiation Physics and Chemistry $83,1112013$. 
44. Hoffmann E., N., Takashi, Haibara-gun, Shizuoka-ken (FUJIFILM Co), EP 2042309 A2, September 26, 2008.

45. Jin, L. Y.; Hou, R.; Chen, T.; Fang, M.; Mah, S.; Yin, B., Fibers and Polymers 8, 1432007. 


\section{Supplementary data:}

\section{Cationic water dispersion of bio-sourced crosslinked polyurethane}

Laurence Pessoni, ${ }^{a, b}$ Prakash Sane, ${ }^{a, b}$ Etienne Grau, ${ }^{* a, b}$ Henri Cramail *a,b

Characterization of polyurethanes obtained:

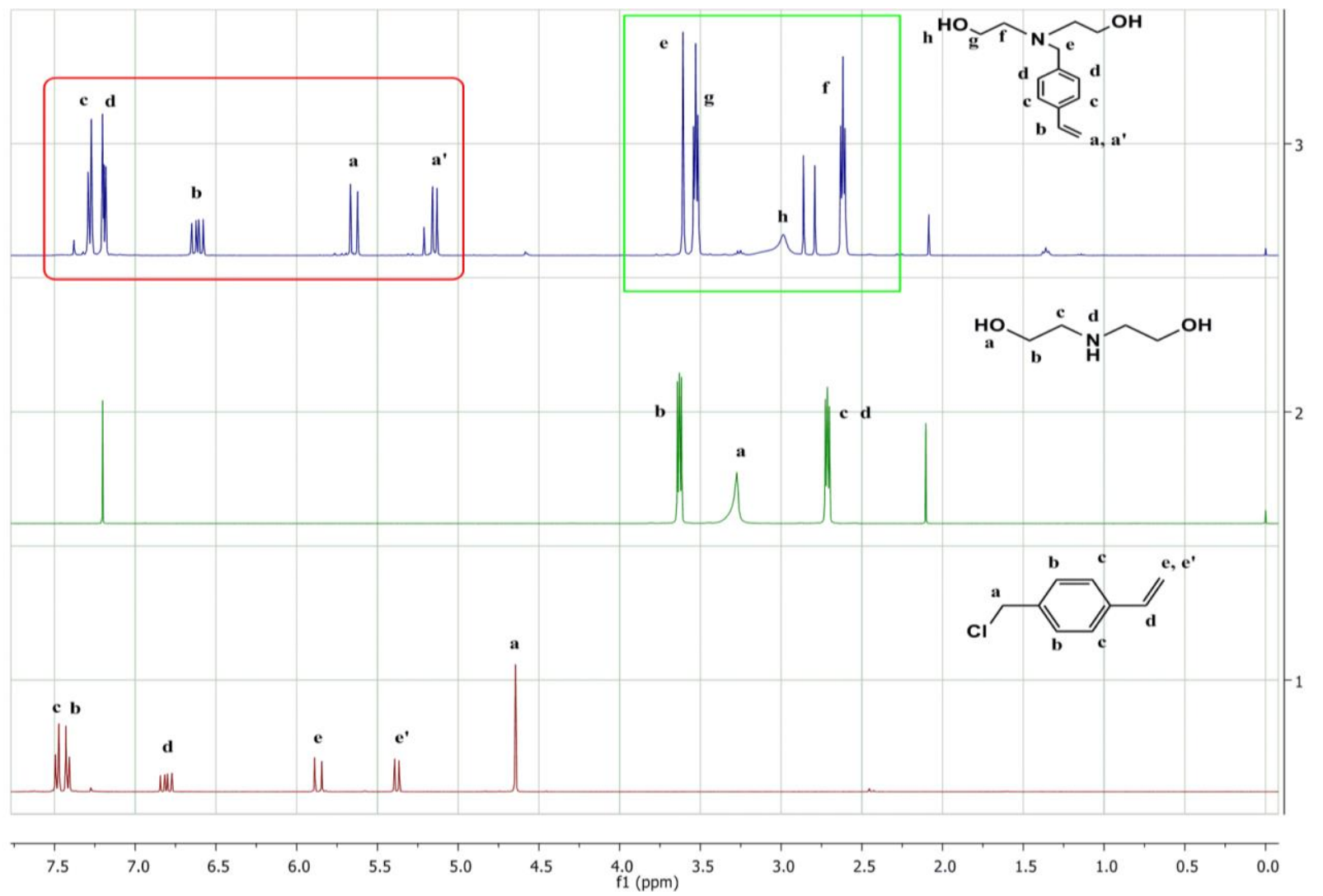

FIGURE S1 NMR spectra in $\mathrm{CDCL}_{3}$ of VBDA in blue, of MDEA in green and VBC in red. 
TABLE S1 Molecular weight in number of WPU in g. $\mathrm{mol}^{-1}$

\begin{tabular}{ccccc}
\hline & IPDI & $\mathrm{HDI}$ & $\mathrm{MDI}$ & $\mathrm{HMDI}$ \\
\hline & $\mathrm{Mn}(\oplus)$ & $\mathrm{Mn}(\oplus)$ & $\mathrm{Mn}(\oplus)$ & $\mathrm{Mn}(\oplus)$ \\
\hline Priplast & 5800 & 5800 & 5800 & 5800 \\
\hline 1 & $35000(1.7)$ & $19700(1.8)$ & $16200(1.2)$ & $20600(1.6)$ \\
2 & $10900(1.7)$ & $20800(1.6)$ & $27000(1.5)$ & $21100(1.5)$ \\
3 & $18300(1.7)$ & $66000(1.3)$ & $9700(1.6)$ & $23900(1.7)$ \\
4 & $14700(1.4)$ & $17600(1.5)$ & $11300(1.8)$ & $23200(1.6)$ \\
5 & $12200(1.5)$ & $18300(1.6)$ & $13500(1.7)$ & $11700(1.5)$ \\
6 & $10100(2.1)$ & $20900(1.6)$ & $18100(1.8)$ & $45700(1.7)$ \\
7 & $13900(1.5)$ & $19100(1.5)$ & $11600(1.9)$ & $22300(1.8)$ \\
8 & $13800(1.5)$ & $23900(1.7)$ & $17400(1.8)$ & $23800(1.9)$ \\
9 & $10300(1.6)$ & $27800(1.7)$ & $21900(1.8)$ & $39200(1.6)$ \\
10 & $20600(1.8)$ & $26300(1.9)$ & $16800(1.7)$ & $23100(1.6)$ \\
11 & $12500(1.8)$ & $20400(2.0)$ & $18900(1.8)$ & $36500(1.8)$ \\
12 & $16300(1.8)$ & $49300(2.6)$ & $20400(1.8)$ & $26100(1.8)$ \\
\hline Average & 15700 & 27500 & 18000 & 26400 \\
\hline
\end{tabular}

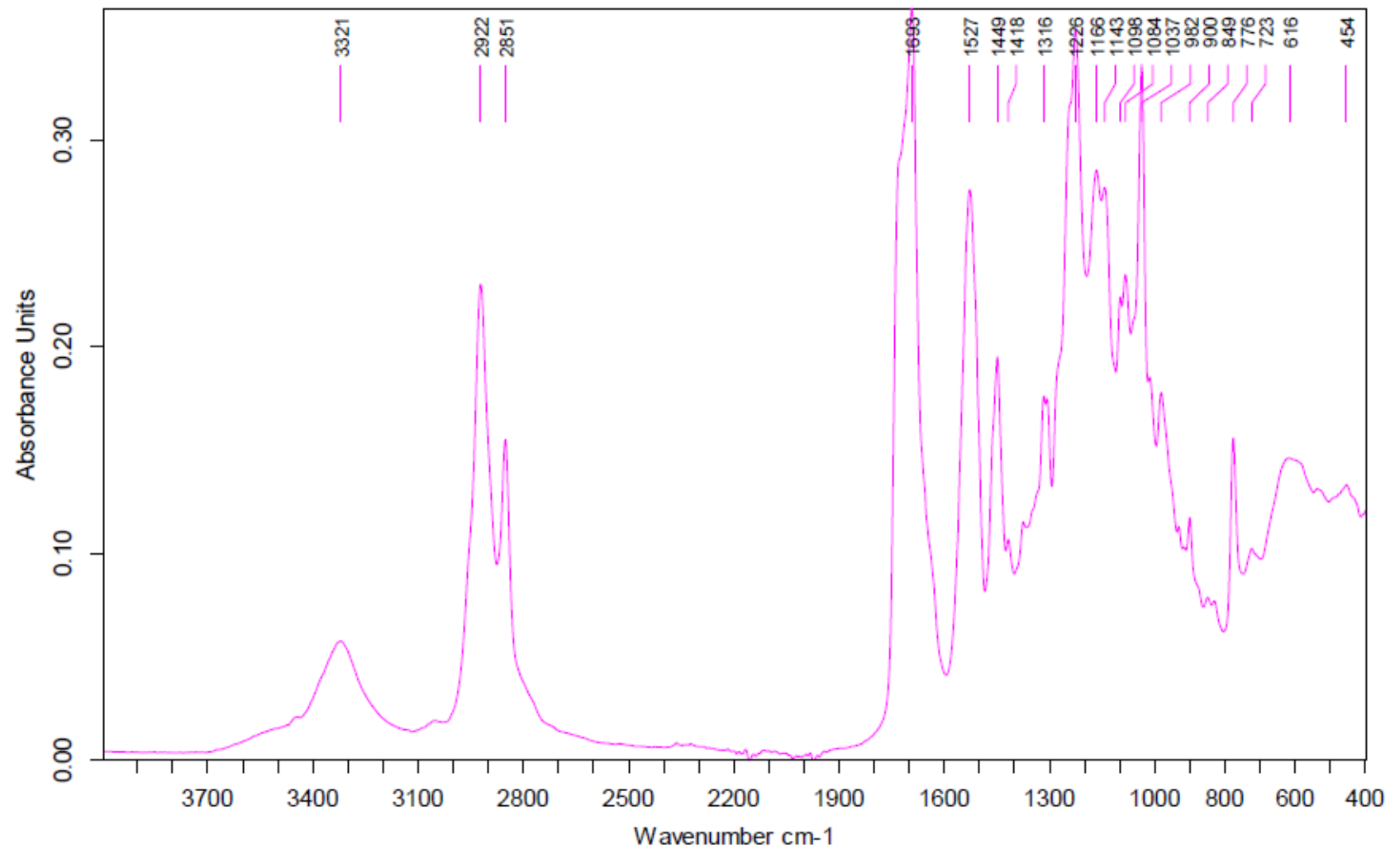

Figure S2 Spectrum of ATR-IR of film “9” realized with HMDI. 
TABLE S2 TGA analysis of WPU films before (A) and after (B) irradiation

\begin{tabular}{c|cc|cc|cc|cc|}
\hline TGA & \multicolumn{2}{|c|}{ IPDI } & \multicolumn{2}{|c|}{ MDI } & \multicolumn{2}{|c|}{ HDI } & \multicolumn{2}{|c}{ HMDI } \\
\hline Sample & A & B & A & B & A & B & A & B \\
\hline 1 & 249 & - & 252 & - & 258 & - & 271 & - \\
2 & 230 & - & 240 & - & 263 & - & 259 & - \\
3 & 239 & - & 226 & - & 256 & - & 271 & - \\
4 & 237 & 263 & 228 & 237 & 269 & 258 & 267 & 274 \\
5 & 209 & 250 & 267 & 228 & 265 & 253 & 270 & 263 \\
6 & 259 & 270 & 243 & 230 & 269 & 249 & 248 & 278 \\
7 & 244 & 265 & 233 & 229 & 270 & 250 & 270 & 262 \\
8 & 248 & 255 & 244 & 240 & 266 & 243 & 247 & 261 \\
9 & 250 & 261 & 223 & 224 & 263 & 232 & 270 & 268 \\
10 & 228 & 262 & 235 & 231 & 258 & 243 & 253 & 254 \\
11 & 252 & 266 & 215 & 212 & 243 & 235 & 263 & 266 \\
12 & 249 & 262 & 207 & 205 & 228 & 228 & 251 & 252 \\
\hline
\end{tabular}

TABLE S3 DSC analysis of WPU films before (A) and after (B) irradiation

\begin{tabular}{|c|c|c|c|c|c|c|c|c|}
\hline \multicolumn{1}{c|}{} & \multicolumn{8}{|c|}{ cationique } \\
\cline { 2 - 9 } & \multicolumn{2}{|c|}{ IPDI } & \multicolumn{2}{c|}{ MDI } & \multicolumn{2}{c|}{ HDI } & \multicolumn{2}{c|}{ HMDI } \\
\cline { 2 - 10 } & A & B & A & B & A & B & A & B \\
\hline 1 & $-45,29$ & - & $-39,42$ & - & $-50,63$ & - & $-47,70$ & - \\
2 & $-45,37$ & - & $-41,14$ & - & $-49,82$ & - & $-47,80$ & - \\
3 & $-48,24$ & - & $-41,17$ & - & $-51,38$ & - & $-46,70$ & - \\
4 & $-47,47$ & $-47,40$ & $-38,65$ & $-40,03$ & $-50,02$ & $-51,02$ & $-45,14$ & $-47,86$ \\
6 & $-44,67$ & $-46,12$ & $-36,56$ & $-32,44$ & $-49,51$ & $-51,28$ & $-47,76$ & $-48,48$ \\
7 & $-44,99$ & $-43,34$ & $-36,04$ & $-33,47$ & $-50,14$ & $-48,21$ & $-44,49$ & $-42,72$ \\
8 & $-44,84$ & $-46,69$ & $-36,61$ & $-42,19$ & $-49,45$ & $-50,31$ & $-45,99$ & $-47,48$ \\
9 & $-40,43$ & $-47,12$ & $-37,06$ & $-31,33$ & $-50,21$ & $-49,81$ & $-44,48$ & $-46,23$ \\
10 & $-49,92$ & $-47,81$ & $-35,51$ & $-39,82$ & $-51,29$ & $-50,10$ & $-47,52$ & $-45,30$ \\
11 & $-51,41$ & $-45,80$ & $-36,62$ & $-37,80$ & $-47,22$ & $-49,72$ & $-49,99$ & $-44,20$ \\
12 & $-44,87$ & $-47,89$ & $-43,11$ & $-42,60$ & $-49,70$ & $-49,68$ & $-49,38$ & $-44,20$ \\
\hline MOY & $-49,60$ & $-44,74$ & $-39,53$ & $-39,95$ & $-49,56$ & $-51,82$ & $-46,11$ & $-47,00$ \\
\hline
\end{tabular}




\section{Characterization of dispersions:}

Others dispersion tests:

For all the water dispersion obtained, 1.1 equivalent of acetic acid to MDEA was added. For example, the sample 4 with HMDI did not lead a good dispersion. But, VBDEA can be also quaternized. Therefore, dispersion could be improved with the addition of more acetic acid in order to have 1.1 equivalents of crosslinker plus emulsifier (sample 4', TABLE S4 and Figure S4). In this condition dispersion obtained was stable. Particle size obtained is $71 \mathrm{~nm}$ with a PDI at 0.209. However, VBDEA alone (sample 13 with HMDI) did not lead to good dispersion in the same proportion than MDEA (sample 3 with HMDI).

TABLE S4 Dispersion tests

\begin{tabular}{cccccc}
\hline & $\begin{array}{c}\text { Priplast } \\
\text { mmol }\end{array}$ & $\begin{array}{c}\text { VBDEA } \\
\text { mmol }\end{array}$ & $\begin{array}{c}\text { MDEA } \\
\text { mmol }\end{array}$ & $\begin{array}{c}\text { Acetic acid } \\
\text { mmol }\end{array}$ & Dispersion \\
\hline Sample 4 & 3 & 1.5 & 2.25 & $2.47^{1}$ & No \\
Sample 4' & 3 & 1.5 & 2.25 & $4.13^{2}$ & Yes \\
Sample 3 & 3 & 0 & 6 & $6.6^{1}$ & Yes \\
Sample 13 & 3 & 6 & 0 & $6.6^{3}$ & No \\
\hline
\end{tabular}

${ }^{1} 1.1$ Equivalent compare to MDEA

21.1 Equivalent compare to MDEA and VBDEA

${ }^{3} 1.1$ Equivalent compare to VBDEA

TEM images:
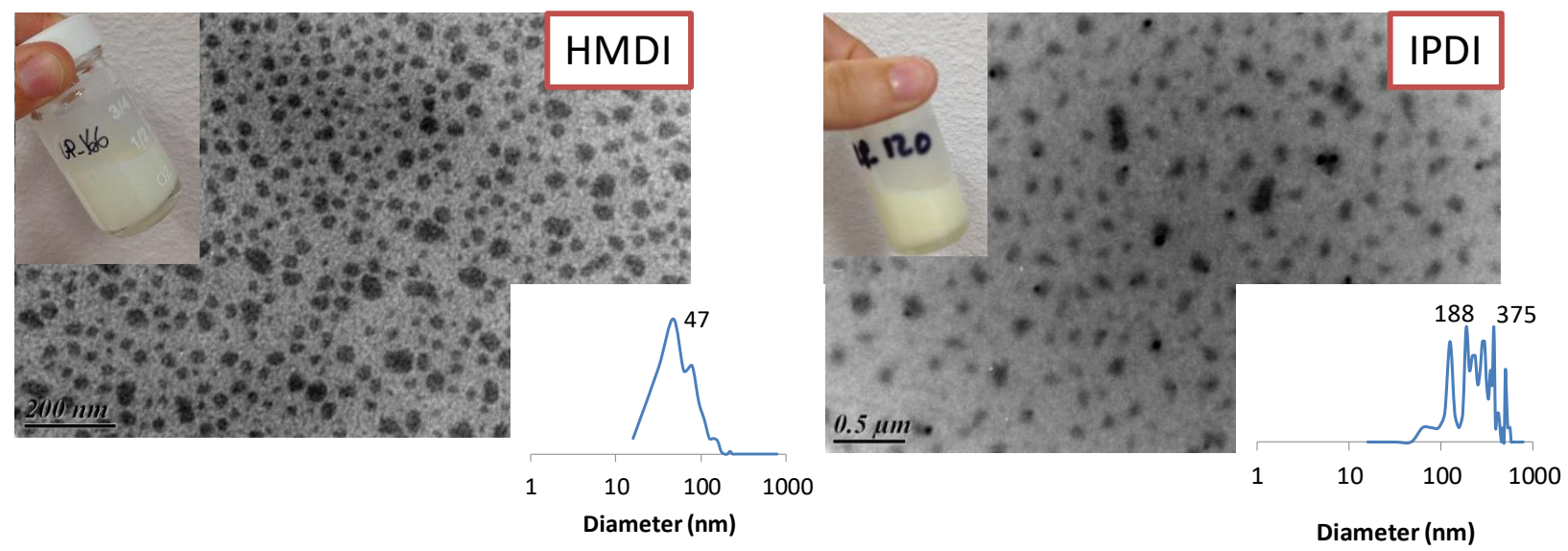

FIGURE S3 TEM images and TEM particles size distribution of WPU dispersion realized with HMDI (sample 7) and HDI (sample 9). 




FIGURE S4 Picture of dispersion obtained with HMDI as isocyanate of the sample 4 with 1.1 equivalent of acetic acid compare to MDEA (left) and 1.1 equivalent of acetic acid compare to MDEA plus crosslinker (right) 
Characterization of films:


MDI


FIGURE S5 Percentage of soluble part of films obtained from HDI, IDPI and MDI in acetone and in THF; a: polyol, b: crosslinker and c: MDEA. 
Tensile Strength (MPa)
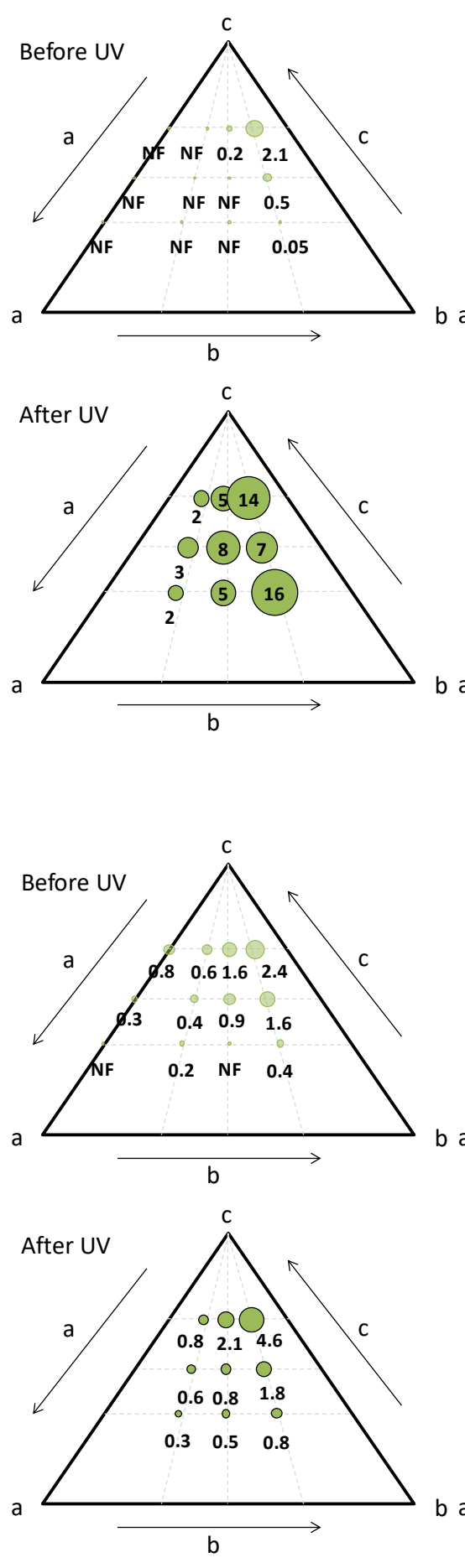

IPDI

Elongation (\%)
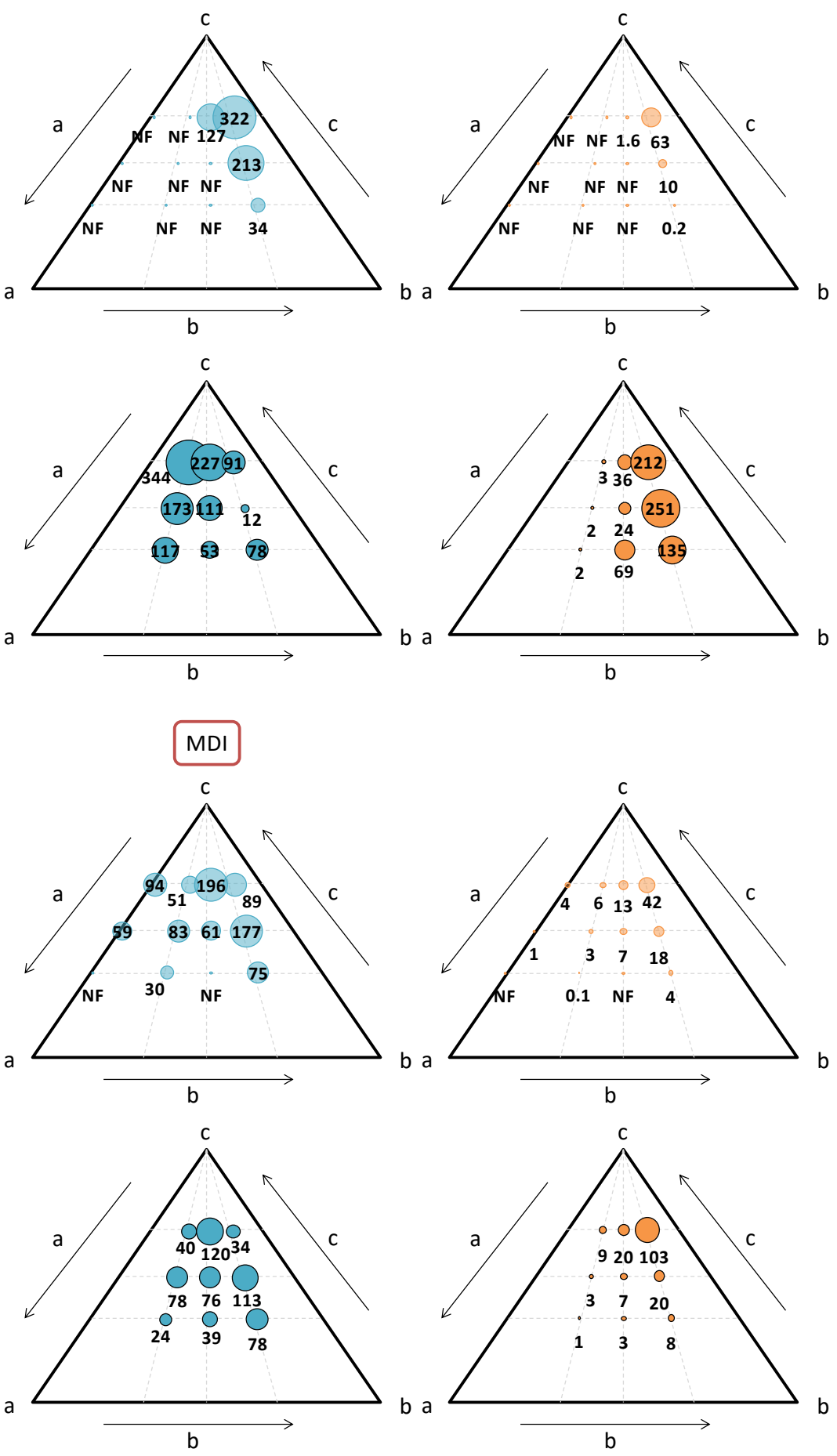


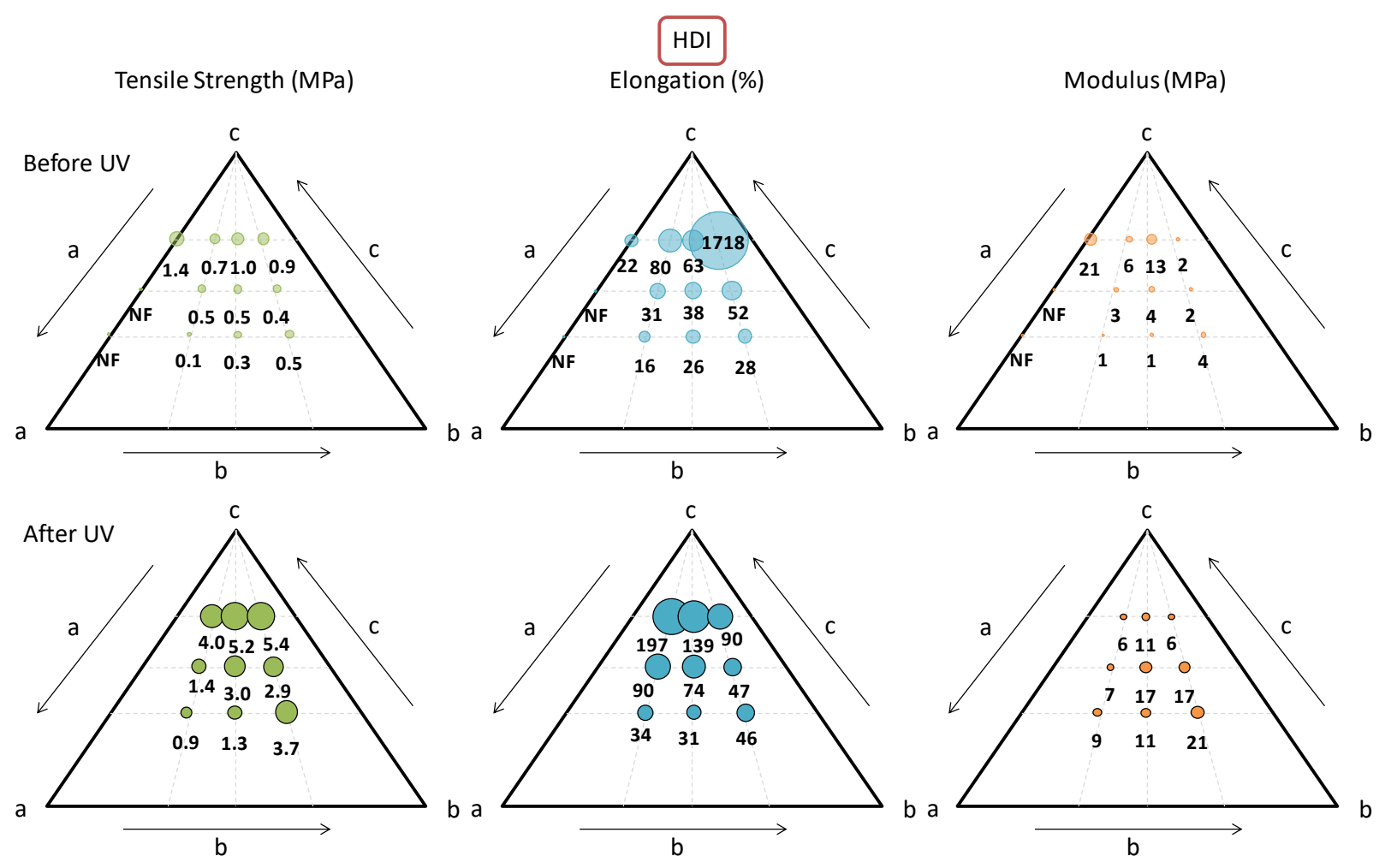

FIGURE S6 Mechanical properties of WPU films realized with IPDI, MDI and HDI before irradiation to the top and after irradiation to the bottom: in green is represented the tensile strength, in blue the elongation and in orange the modulus; " $a$ " is the polyol, " $b$ " is the crosslinker and " $c$ " is the emulsifier; $\mathrm{NF}=$ No film. 


\section{Before UV}

HDI

a



IPDI


After UV
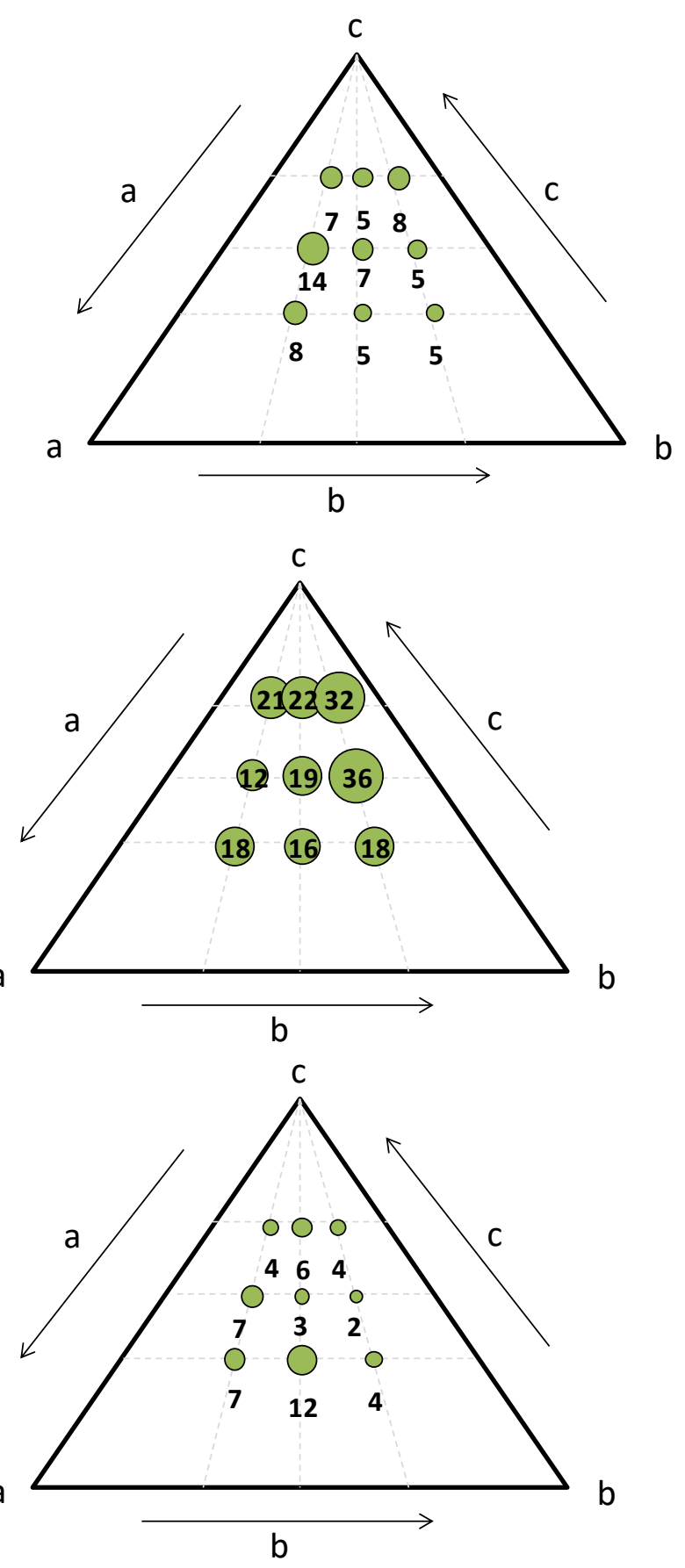

FIGURE S7 Water absorption of WPU films obtained with HDI, IPDI and MDI before UV (right) and after UV (left): $\boldsymbol{Q}=\frac{\boldsymbol{w}_{f}-\boldsymbol{w}_{\boldsymbol{i}}}{\boldsymbol{w}_{\boldsymbol{i}}} \times \mathbf{1 0 0}(\%) ; w_{\mathrm{f}}=$ mass of the film after swelling; $w_{\mathrm{i}}=$ initial mass of the film; NF = No film, a: polyol, b: crosslinker and c: MDEA. 